\title{
Explorando Soluções Internacionais: o Caso dos Frigoríficos Brasileiros
}

\author{
Exploring Solutions International: The Case of Brazilian Refrigerators \\ Daniela Maria Pozzobon \\ Doutoranda em Administração pela USP \\ Universidade de São Paulo
}

\begin{abstract}
Resumo
Este artigo compreende um estudo das abordagens de internacionalização praticadas pelos frigoríficos brasileiros sob as teorias econômicas, tendo como objetivos: (i) analisar: os modos de entrada no exterior; os motivos econômicos de internacionalização sob o impacto dos diferentes ambientes institucionais; o grau de diversificação ou especialização possibilitado pelos investimentos realizados no exterior; como a coordenação da firma é organizada no exterior; (ii) verificar a aderência dos processos de internacionalização dos frigoríficos brasileiros com as teorias econômicas de internacionalização. As principais conclusões foram de que os processos de internacionalização dos frigoríficos brasileiros corroboram não só a teoria econômica de Dunning (1993), que sugere a busca de mercados, ativos, recursos e eficiência; e o Paradigma Eclético (DUNNING, 1980), que alude para a busca de três tipos de vantagens: propriedade, localização e internalização, principalmente, mas também confirmam as teorias de Hymer (1968), Aliber (1970), McManus (1972), Knickerbocker (1973), Buckley e Casson (1976), Grahan (1998).
\end{abstract}

Palavras-chave: Internacionalização. Frigorífico. Teoria Econômica.

\section{Abstract}

This article includes a study of internationalization's approaches practiced by the of Brazilian refrigerators under the economic theories, with the following objectives: (i) review: the modes of entry in other countries; the economic motives for internationalization under the impact of different institutional environments; the degree of diversification and specialization possible by investments in abroad, such as coordination of the firm is organized overseas, (ii) monitor the adherence of procedures for the internationalization of Brazilian refrigerators with the economic theories of internationalization. The main findings were that the process of internationalization of Brazilian refrigerators corroborate not only the economic theory of Dunning (1993), which suggests the search for markets, assets, resources and efficiency; and the eclectic paradigm (DUNNING, 1980), which refers to the search for three kinds of advantages: ownership, location and internalization, mainly, but also confirm the theories of Hymer (1968), Alibi (1970), McManus (1972), Knickerbocker (1973), Buckley and Casson (1976), Grahan (1998).

Keywords: Internationalization. Refrigerator. Economic Theory. 


\section{Introdução}

Os últimos cinqüenta anos foram um período de crescente desenvolvimento, no qual as principais teorias sobre a moderna empresa multinacional têm sido desenvolvidas. Entretanto, as teorias apresentadas podem variar consideravelmente e a demarcação entre elas algumas vezes não é clara.

Ainda que o processo de internacionalização de empresas possa ser analisado sob uma variedade de caminhos (econômico, comportamental, competitividade, operações, para citar os principais), a lente aqui escolhida foi a econômica.

$\mathrm{O}$ assunto merece ser estudado com detalhes por dois motivos principais. Em primeiro lugar nota-se, conforme dados da Unctad (2007), que embora o Brasil já venha recebendo investimentos diretos do exterior há um pouco mais de tempo, é recente o processo de expansão das suas corporações, principalmente considerando-se o agronegócio da carne. Atualmente, os números do Brasil, considerando-se o fluxo de investimentos diretos externos/internos, têm apresentado significativa evolução nos investimentos feitos pelo Brasil em outros países, e manutenção dos investimentos realizados por empresas de outros países no Brasil.

Em relação à carne bovina, por exemplo, o Brasil é considerado o país que possui o maior rebanho do mundo para fins comerciais (USDA, 2007). Vantagens competitivas da carne bovina brasileira podem ser citadas: menor custo de produção de bovinos do mundo (mão-de-obra barata e disponível em larga escala, terras com baixo custo, clima favorável); boi verde, alimentado exclusivamente no pasto. As exportações brasileiras de carne bovina aumentaram em aproximadamente $27,5 \%$, em média, de 2000 a 2006 e a situação do mercado doméstico é a de que alcançou níveis de consumo muito próximos aos dos países com melhor desempenho econômico que o Brasil. Embora sendo o segundo maior produto na pauta de exportações, a carne bovina brasileira, até então, tem enfrentado bloqueio à sua expansão internacional. O motivo principal é o conjunto de embargos que veta o acesso dos frigoríficos nacionais a mais de 50\% do mercado mundial (CNA, 2007). São restrições sanitárias que dificultam o acesso dos frigoríficos aos EUA, Canadá e México, além de outros mercados importantes pelo mundo. Sendo assim, em segundo lugar motivando esta pesquisa, considerase que o processo de internacionalização das corporações brasileiras do agronegócio da carne bovina e frango é recente e merece ser estudado com detalhes, principalmente sob a ótica das teorias econômicas.

Logo, questiona-se "as abordagens praticadas pelos frigorificos brasileiros, nos seus recentes processos de internacionalização, são coerentes com as teorias econômicas propostas?"

O objetivo geral deste será o de "analisar, sob a ótica das teorias econômicas de internacionalização, as abordagens praticadas pelos frigoríficos brasileiros nos seus recentes processos de internacionalização”. De maneira específica, os objetivos deste estudo são os seguintes: (i) analisar: os modos de entrada no exterior; os motivos econômicos de internacionalização sob o impacto dos diferentes ambientes institucionais; o grau de diversificação ou especialização possibilitado pelos investimentos realizados no exterior; como a coordenação da firma é organizada no exterior; (ii) verificar a aderência dos processos de internacionalização dos frigorificos brasileiros com as teorias econômicas de internacionalização.

\section{Referencial Teórico}

Enquanto as teorias econômicas de internacionalização explicam o processo de internacionalização através do nível de agregação da macroeconomia, das indústrias e das firmas; as teorias de operações internacionais o explicam a partir dos diferentes tipos de fábricas implantadas no exterior; e as teorias comportamentais enfatizam os problemas 
associados com a aprendizagem, o comprometimento, e os aspectos culturais, sendo que estas últimas vêem a internacionalização como um processo gradual, envolvendo aprendizagem. Além disso, o processo de internacionalização também tem sido estudado sob a ótica da competitividade (PORTER, 1986).

Outro debate importante na literatura são os motivos que justificam as empresas a se internacionalizarem. De acordo com pesquisas da escola de Uppsala (JOHANSON; VAHLNE, 1977), motivos vinham não só da teoria econômica, mas também de outras teorias, como Resource Based View (PENROSE, 1959) e os trabalhos de Cyert e March (1963). Já de acordo com a teoria comportamental das multinacionais (VERNON, 1966) as decisões de internacionalização são melhor entendidas como resultantes de: rivalidade, incerteza, timing de decisões.

O conceito teórico em relação às teorias econômicas da internacionalização pode vir da teoria do comércio internacional e produção internacional (VERNON; 1966; 1974; 1979; GRUBER et. al.; 1967); principalmente investimento direto no exterior ("IDE" ou Foreign Direct Investment "FDI") (KNICKERBOCKER, 1973; GRAHAM, 1998); exportação, licenciamento e FDI (ALIBER, 1970); produção direta no exterior versus licenciamento (McMANUS, 1972; BUCKLEY, CASSON, 1976; RUGMAN, 1981; HENNART, 1982; CAVES, 1971; 1982); exportação, FDI, licenciamento/franchising, alianças (DUNNING, $1977 ; 1980 ; 1997)$.

O fenômeno da internacionalização, em primeiro lugar, começou com as questões econômicas. Nas primeiras análises, focalizou-se a questão do investimento externo (HYMER, 1976) considerando-se as peculiaridades dos investimentos externos realizados pelas grandes empresas para a produção e negócios diretos. Isto é o que o autor chama de investimentos diretos no exterior. Hymer (1976) preocupa-se com a necessidade de se diferenciar os investimentos do tipo puramente financeiro daquele do tipo portfolio. Segundo sua análise, a questão-chave que diferencia os dois reside no controle. Afirma, ainda, que a teoria neoclássica, baseada em taxas de juros, não pode explicar os investimentos diretos no exterior e suas motivações.

A teoria de Hymer (1976) assume que a produção direta no exterior (FDI) envolve custos extras e riscos, devido, em particular, aos seguintes fatores: custos de comunicação e de aquisição de informação em geral, onde estes custos são encadeados com as diferenças culturais, lingüísticas, legais, econômicas e de ambiente político nas quais a empresa terá que operar no país hospedeiro; custos atribuídos ao tratamento menos favorável dado pelos governos dos países hospedeiros; custos e riscos de alteração de taxas de flutuação.

Hymer (1976) refuta o argumento de que os investimentos diretos no exterior (FDI) são motivados pela procura de baixos custos de produção em outros países. Ele argumenta que, se isso fosse a principal razão para o investimento, ter-se-ia dificuldade para explicar o por quê de as firmas locais não competirem com sucesso com as estrangeiras. Logo, a suposição-chave na sua teoria, na busca pelos determinantes de produção internacional (FDI), é a existência de falhas/imperfeições de mercado. As imperfeições de mercado podem ser devido a: imperfeições nos mercados de bens; imperfeições nos elementos de mercado; economias de escala interna e externa; interferência do governo com a produção ou comércio.

Sendo assim, segundo Hymer (1976), dois são os determinantes de investimento direto no exterior (FDI), visto a existência de falhas de mercado: a existência de vantagens específicas que podem ser exploradas no exterior e que estão exauridas no seu país; e a remoção de conflitos. Ou seja, os investimentos diretos no exterior têm diferenças, de acordo com o que o país oferece de vantagens/desvantagens. Uma terceira razão, inclui o autor, como determinante para FDI, é uma estratégia de diversificação.

A última análise trabalhada por Hymer (1976) leva à conclusão de que, se por um lado a empresa multinacional é uma força potente porque consegue planejar e organizar a 
produção sobre uma escala internacional levando para um aumento na produtividade e expansão de novas tecnologias e novos produtos, por outro lado, a principal contradição é de que a empresa multinacional opera com um melhor planejamento interno e com pouco conhecimento sobre o planejamento externo.

Em outro trabalho, Hymer (1968) é fortemente influenciado pela literatura da Nova Economia Institucional de Coase $(1937 ; 1960)$, primeiro autor que trata da questão da coordenação (e do conseqüente crescimento da firma) e dos custos de transação. Seguindo o estudo de Coase $(1937 ; 1960)$ para a teoria da internacionalização, Hymer (1968) acentua a relevância das imperfeições de transações no mercado como a razão para o crescimento interno da firma, ou seja, combinação de economias de escala e vantagens comparativas de coordenação da produção via hierarquia interna versus coordenação através do mercado. Hymer (1968) concentra sobre as vantagens da integração vertical, quando antecipa alguns dos trabalhos da escola da internalização.

Um trabalho subseqüente na teoria econômica de internacionalização é o de Aliber (1970), o qual desenvolve uma teoria de investimento direto no exterior (FDI) em que objetiva explicar quando e por que os mercados externos são fornecidos em um desses métodos: produção doméstica através de exportação; produção no país hospedeiro através de acordo de licenciamento envolvendo firmas locais; ou via produção direta no exterior (FDI). Sua teoria encontra-se, então, preocupada em explicar todas as principais modalidades de internacionalização. Ele começa assumindo que FDI envolve custos extras e desvantagens relacionadas com a administração da empresa à distância, o que faz surgir a necessidade de olhar vantagens compensadoras. Segundo ele, a teoria de FDI deve analisar a fonte de tais vantagens. O trabalho de Aliber (1970) reside na questão: qual tem a melhor vantagem econômica: produção doméstica, licenciamento, ou FDI? A análise trata, então, do tradeoff entre economias de escala com produção doméstica e barreiras tarifárias com exportação.

A extensão da teoria dos custos de transação da firma em geral (COASE 1937; 1960; WILLIAMSON, 1975) para a firma internacional é devida a McManus (1972); Buckley e Casson (1976) com outras maiores contribuições incluindo Rugman (1981); Hennart (1982) e Caves (1982), principalmente.

McManus (1972) acredita que a existência de custos de transação torna-se a chave do por que das empresas multinacionais estabelecerem subsidiárias no exterior, as quais operam sob controle diretamente centralizado (integração vertical) ao contrário de operar via mercado.

Buckley e Casson (1976) continuam a teoria de McManus (1972) e partem dos seguintes pressupostos: firmas maximizam lucros em um mundo de imperfeições de mercado; quando os mercados de produtos intermediários são imperfeitos, existe um incentivo para desviá-los criando mercados internos (integração vertical), isso envolve criação de propriedade comum e controle das atividades as quais são ligadas pelo mercado; internalização dos mercados através dos limites nacionais gera empresas multinacionais.

Vernon (1974), por sua vez, desenvolve pesquisa sobre a ligação entre a decisão de operar internacionalmente e estruturas oligopolísticas, identificando três estágios de oligopólios (oligopólio baseado na inovação, oligopólio maduro, e oligopólio envelhecido), caracterizados por diferentes elementos de vantagens competitivas sobre a parte do oligopólio em relação aos rivais. Estas vantagens, segundo o autor, podem atuar como barreiras para entrantes no mercado.

Knickerbocker (1973) desenvolveu seu trabalho na mesma linha de pensamento de Vernon (1966). Sua pesquisa consiste de um modelo teórico informal contendo razões que levam certas firmas ao comportamento de investir diretamente no exterior (FDI) e como tal comportamento é vinculado com o mercado. Knickerbocker (1973) começa definindo FDI como o fluxo de capital resultante de investimentos de uma empresa em ativos fora de seu 
país de origem, a fim de controlar totalmente ou parcialmente a operação desses ativos. Assim, ele define como investimento agressivo, o estabelecimento da primeira subsidiária em uma dada indústria e em um dado país e, como investimento defensivo, o estabelecimento das subsidiárias subseqüentes.

Visto que o modelo de Knickerbocker (1973) é baseado em estruturas oligopolísticas, ele define oligopólio como uma estrutura caracterizada por poucos vendedores; produtos que são substitutos próximos; interdependência de mercado substancial entre as políticas do competidor destas firmas. O equilíbrio oligopolístico é definido como um estado de negócios entre os vendedores tal que todos rivais aproximadamente têm as mesmas competências competitivas, existe pouca possibilidade para um rival achar que pode, impune, melhorar sua posição de mercado à custa de outro.

Outras circunstâncias que podem ter levado as firmas americanas (a pesquisa realizada baseou-se nestas) para investimento direto no exterior (FDI), mais do que exportação e licenciamento, conforme Knickerbocker (1973), são as barreiras tarifárias e não-tarifárias e poder oferecer serviços pós-venda. $\mathrm{Na}$ visão do autor, os oligopólios se formam através de três configurações: pelo desenvolvimento de novos produtos; por vantagens de escala; pelas vantagens que são adquiridas, como vantagens que vão sendo adquiridas com produção, marketing e administração e que podem gradualmente eliminar os rivais.

Knickerbocker (1973) insere também a questão da incerteza e da aprendizagem quando analisa que investimentos em países estrangeiros envolvem uma considerável quantidade de incerteza e que a firma aprende com cada movimento e melhora sua habilidade para examinar cuidadosamente o mundo e reduz, assim, as incertezas. No centro da teoria de Knickerbocker (1973) está a estrutura oligopolística, e a incerteza e o risco são os determinantes de FDI.

Mais recentemente, Graham (1998) usa uma estrutura oligopolística para explicar as estratégias de localização de grandes empresas americanas e européias.

Outra teoria econômica importante da internacionalização de empresas é o Paradigma Eclético (DUNNING, 1980), um quadro sistêmico de referência (holistic framework) a partir do qual é possível identificar e avaliar a significância dos fatores que influenciam tanto a decisão inicial de uma empresa de produzir no exterior quanto o crescimento deste tipo de produção. São três as vantagens específicas, de acordo com Dunning (1980), vantagem específica de propriedade (O- ownership) está relacionada com a natureza e/ou nacionalidade da propriedade; vantagem específica de localização (L- location) está relacionada ao local onde se implantam as operações no exterior; vantagem específica de internalização (Iinternalization), é obtida ao se utilizar a estrutura da empresa para transações internacionais ao invés de mecanismos de mercado, ou seja, internalizar transações ao invés de fazer via mercado. No caso da última, a variável decisória é o custo (nesse caso, de transação) e a decisão é pela hierarquia, ou seja, a relação matriz versus subsidiária é uma forma de governança de integração vertical, visto que a teoria da internalização tem como pressuposto diminuir os custos de transação.

Caves (1982) foca seu estudo analisando se as operações da firma internacional são realizadas de maneira horizontal, vertical, ou diversificada.

Por fim, Dunning (1993) estuda os motivos de internacionalização de empresas com relação à evolução do país hospedeiro e estratégias das multinacionais e conclui que os motivos podem ser procura de recursos; procura de mercados; procura de eficiência; ou procura de ativos.

\section{Método De Pesquisa}

Esta pesquisa caracteriza-se como multi-casos (YIN, 1994), pelo fato de se ter encontrado uma pequena população de empresas a serem analisadas, ou seja, foram 
pesquisados os frigoríficos brasileiros que até então realizaram modalidades de internacionalização, quais sejam: JBS, Marfrig e Sadia. Os dados desta pesquisa são secundários. A coleta de dados foi realizada através de pesquisas nos sites das empresas, em documentos publicados pelas empresas disponíveis on line e na mídia jornalística publicada no período de março a dezembro de 2007.

\section{Resultados}

\subsection{Apresentação dos Resultados}

\section{O Caso JBS S. A.}

O JBS foi a primeira empresa a entrar no ramo de atividades de frigorífico no Brasil, em 1953, em Anápolis/GO.

\section{a) Processo de Internacionalização}

Em 1997, o JBS inicia suas exportações de carne in natura. Os produtos da empresa são, em 2007, exportados para mais de 500 clientes localizados em mais de 110 países. No Brasil, seus produtos são vendidos para mais 6.000 clientes, incluindo varejistas, restaurantes e curtumes.

Em agosto de 2005, inicia aquisições na Argentina. Foram adquiridas 3 plantas da Swift Armour e 2 plantas da Companhia Elaboradora de Produtos Alimentícios (CEPA), totalizando 5 unidades: Rosário, Venado Tuerto, Pontevedra, São José e Berazategui. A adquirida planta da Companhia Elaboradora de Produtos Alimentícios (CEPA), em Venado Tuerto, na Província de Santa Fe, até 2005, antes de declarar falência, foi um dos maiores frigoríficos do país, com uma capacidade de abate de 500 cabeças diárias, trabalhando com produtos processados dirigidos ao mercado externo.

No Final de 2006 a empresa continuou suas aquisições, desta vez nos Estados Unidos. Adquiriu a distribuidora americana de produtos industrializados de carne bovina SB Holdings.

No mês de julho de 2007 adquire 100\% da companhia americana Swift Foods \& Company (unidades nos EUA e Austrália), tornando-se a maior empresa de carne bovina em capacidade de abate que gera atualmente mais de 40.000 empregos pelo mundo. Com a aquisição da Swift Foods \& Company nos Estados Unidos, tornou-se a maior multinacional brasileira de alimentos, e maior empresa do mundo no setor de proteínas de origem bovina. Com esta operação entra para o mercado de carne suína e conquista também uma posição expressiva no mercado de carne suína: o posto de terceiro maior produtor e processador de carne suína nos EUA.

Em 2007, a Swift Armour, subsidiária do JBS na Argentina, comprou o Consignaciones Rurales e a fábrica de embalagens Argenvases na Argentina.

O JBS anunciou, em outubro de 2007, a aquisição, por US\$ 20 milhões, do frigorífico argentino Col Car S.A., localizado na cidade de Colonia Caroya, província de Córdoba. A aquisição foi coordenada pela subsidiária da Argentina, Swift Armour. A operação ainda precisa ser aprovada pela Comissão Nacional de Defesa da Concorrência.

A empresa anunciou, ainda, no início de dezembro de 2007 , a aquisição de $50 \%$ das ações da Inalca, uma das principais empresas do setor na Europa e líder do mercado italiano de carne bovina. O negócio inclui a compra da Montana, uma empresa de comida pronta, do mesmo grupo, que será incorporada à Inalca. Ambas são controladas pelo grupo italiano Cremonini. Motivo de entrada: a compra abre novos mercados para o JBS, dentre os quais: grandes multinacionais no setor de fast food, produtores de alimentos industrializados, grandes cadeias de varejo e empresas de distribuição de alimentos (foodservice), além da possibilidade de conseguir agregar a distribuição de alimentos no território europeu e com atuação na Rússia e África. Também, oferece à JBS o acesso à tecnologia de última geração da Inalca, amplamente reconhecida, bem como aos produtos de maior valor agregado 
comercializados sob a marca Montana. Para a Cremonini (que já opera em três áreas de negócio: produção, distribuição e abastecimento), a transação garante acesso privilegiado às principais fontes mundiais de fornecimento de carne bovina, fortalecendo, assim, o controle global de toda a cadeia de abastecimento.

A Inalca S.p.A. opera através de uma estrutura de produção composta de 6 unidades na Itália, especializada por linha de produção, e 9 instalações internacionais localizadas na Europa, Rússia e na África. A Montana Alimentari S.p.A. é uma das principais operadoras italianas na produção, comercialização e distribuição de carnes curadas, aperitivos e produtos prontos para consumo, oferecendo mais de 230 produtos. A empresa apresenta uma estrutura industrial de 4 unidades, especializadas por tipo de produção e localizadas em áreas definidas como Denominação de Origem Protegida (D.O.P) e Indicação Geográfica Protegida (I.G.P). A empresa é também uma das principais operadoras no mercado italiano de carne enlatada, com $22 \%$ de participação de mercado, e de produtos fatiados.

\section{b) Integração Vertical}

O JBS controla todos os elos na cadeia através do confinamento, da divisão de alimentos, canais próprios de distribuição, divisão de transportes e indústria de embalagens.

A empresa tem subsidiárias no Chile, Egito, Estados Unidos, Inglaterra e Rússia que atuam como distribuidores de seus produtos naqueles países, o que lhe possibilita atender melhor seus clientes, garantir o acesso a tais mercados, otimizar seu mix de produtos e, ao mesmo tempo, aumentar sua rentabilidade por meio da redução dos seus custos operacionais.

Com as aquisições com foco na distribuição nos EUA (2006) e na Itália (2007), o JBS torna-se uma empresa com forte foco em distribuição de alimentos.

Além dos baixos custos de produção que o JBS possui pelo fato de suas operações estarem localizadas e eficientemente estruturadas no Brasil e na Argentina, sua estrutura de custos é ainda beneficiada por um custo atrativo de gado, escala de produção e eficiência logística.

\section{c) Grau de Especialização/Diversificação}

O JBS adquiriu a Swift \& Company, empresa que fornece produtos bovinos e suínos de qualidade aos consumidores há 150 anos. Com pensamento inovador, a Swift tornou-se uma indústria pioneira de novas idéias, produtos e tecnologia. O compromisso continua hoje com esforços para desenvolver e fornecer produtos bovinos e suínos com praticidade e extremo sabor. Além de fornecer para o maior mercado consumidor de industrializados e de carne fresca, a Swift americana abriu ao JBS a oportunidade de exploração do segmento de carne suína.

\section{O Caso Marfrig}

O Marfrig iniciou suas atividades em 1986, quando abriu seu primeiro negócio e, apenas dois anos depois, já havia se estabelecido como um importante distribuidor de cortes bovinos, suínos, aves e pescado, além de vegetais congelados importados, para uma variada gama de clientes no Estado de São Paulo, incluindo renomados restaurantes. Em 2000, os sócios fundadores da empresa constituíram o Marfrig Frigoríficos e Comércio de Alimentos S.A., (que viria a ser transformado na empresa) e, arrendaram sua primeira planta de abate e processamento em Bataguassu/MS.

\section{a) Processo de Internacionalização}

Em 2001 foi criado o negócio de exportação, quando o Marfrig arrendou sua segunda planta de abate e processamento em Promissão/SP (Promissão I), junto com a marca "GJ", reconhecida no mercado internacional. Por meio de suas plantas no Brasil, Argentina, Uruguai e Chile, o Marfrig exporta seus produtos de carne bovina a clientes distribuidores e atacadistas situados em todos os mercados relevantes, incluindo União Européia, Estados 
Unidos e Japão. Os produtos da empresa são exportados em 2007 a clientes em mais de 50 países.

Em julho de 2006 a empresa ingressou no Chile e constituiu o Marfrig Chile, e em setembro de 2006 comprou 50\% do capital social da Quinto Cuarto.

Em outubro de 2006 adquiriu 3 plantas no Uruguai: Frigoríficos Elbio Rodriguez, La Caballada e Tacuarembó. Motivo de Entrada: fábrica possui tecnologia de última geração, capaz de agradar exigentes mercados.

Em outubro de 2006 adquiriu 100\% do capital da Argentina Breeders \& Packers que possui uma planta de abate na Argentina. Como motivos de entrada, pode-se citar: a AB\&P é líder na Argentina em produção e suprimento de carne de qualidade para supermercados, restaurantes, distribuidores e processadores de todo mundo (Europa, EUA, América Latina e Caribe); alto controle sanitário no país permite exportar para os países mais exigentes; a Argentina tem uma cota de exportação de carnes nobres de 29 mil toneladas, enquanto a cota do Brasil é de 5 mil toneladas.

Em dezembro de 2006 a empresa adquiriu a Inaler, com planta no Uruguai.

Em 2007 iniciou a operação de abate e desossa no Uruguai.

Em agosto de 2007 anunciou um acordo para adquirir o Frigorífico Patagônia, localizado em Comuna Porvenir, na Terra do Fogo, no Chile. O termo do acordo, firmado por meio da subsidiária do Marfrig no Chile, prevê a aquisição de 97,82\% das ações do Frigorífico Patagônia. A empresa chilena tem uma capacidade de abate de 300 mil cabecas de ovinos/ano e exporta para diversos mercados, como União Européia, México, Japão, Rússia, Brasil, Argentina e Israel, dispondo ainda de facilidades para abater "Kosher", alimento preparado segundo os princípios judaicos.

Em setembro de 2007 anunciou aquisição de 70,51\% das ações da empresa Quickfood Argentina. O Quickfood, listado na bolsa de Buenos Aires desde 2002, é líder na produção de alimentos derivados de carne bovina na Argentina. As principais atividades da empresa incluem o abate, produção, processamento e exportação do produto. A empresa opera fábricas com capacidade total de abate de 1.400 cabeças/dia. A Quickfood é a atual líder no segmento de carne bovina na Argentina. Possui 4 unidades para abate, processamento e exportação de carne e derivados para a América Latina, Caribe, Europa e Ásia.

A empresa comunicou, ainda, ter firmado por meio da subsidiária Argentina Breeders \& Packers (AB\&P), cartas de intenções para eventual aquisição da totalidade das ações da Best Beef, unidade localizada em Vivoratá, na província de Buenos Aires, e para a compra das Estâncias del Sur (EDSA), localizadas em Córdoba.

No mesmo período de 2007 , adquiriu $100 \%$ do frigorífico Colonia, no Uruguai, o maior exportador de carne uruguaia, tendo capacidade de abate de 1.200 cabeças/dia.

Com a operação de internacionalização para o Uruguai, transformou-se no maior grupo de gado do Uruguai, tanto no abate quanto na exportação. No Uruguai, o Marfrig é o maior produtor de carne bovina, com capacidade de abate de 1.900 cabeças/dia. Em sua operação uruguaia, a empresa possui ainda capacidade para abate de ovinos.

\section{b) Integração Vertical}

No Brasil, possui uma eficiente central de distribuição e armazenamento estrategicamente situada próximo ao litoral e aos grandes mercados consumidores internos. Por meio de sua eficiente plataforma de distribuição, a empresa entrega produtos de carne bovina e ovina, e também outros produtos alimentícios, tais como batata pré-cozida congelada e pescados (food service), a grandes atacadistas, incluindo algumas das principais redes de supermercados e fast food; e também diretamente a clientes varejistas, tais como restaurantes e butiques de carnes, entre outros. O Marfrig acredita que é o maior distribuidor de food service dos Estados de São Paulo e Rio de Janeiro.

$\mathrm{Na}$ Europa, realiza vendas por meio de sua trading, localizada no Reino Unido. 
$\mathrm{Na}$ Argentina atua, através da AB\&P, em mais de 258.000 hectares de campo e com mais de 177.000 cabeças de gado, incluindo vacas de cria, vaquilhonas e novilhos. Desta forma, controla todas as etapas do processo de produção, desde a cria e o engorde do gado em seus campos, até a elaboração de produtos finais na sua planta frigorífica.

\section{c) Grau de Especialização/Diversificação}

Com a aquisição da Quickfood Argentina, com uma capacidade de processamento que chega a 189 toneladas diárias de hambúrgueres, cortes frios e carne cozida congelada, o JBS através desta subsidiária que é dona da marca de hambúrguer Paty, detém $60 \%$ do mercado argentino e $45 \%$ do mercado uruguaio do produto.

Ampliando a presença em outro setor de proteína animal, o Marfrig adquiriu o frigorífico Mabella, que possui duas plantas de abate de suínos, com capacidade total de 4.200 cabeças/dia, nos Estados de Santa Catarina e Rio Grande do Sul. Detém, ainda, uma linha de produtos embutidos defumados e salgados que representam $20 \%$ de suas vendas, além de $80 \%$ de cortes in natura.

Atualmente, seus produtos encontram-se nos mercados das carnes bovina, ovina e suína.

\section{O Caso Sadia}

A empresa foi fundada em 1944, a partir da aquisição de um frigorífico em dificuldades. Os produtos iniciais nos dois primeiros anos eram a farinha e o farelo de trigo. $\mathrm{O}$ retorno dos investimentos aplicados no moinho permitiu completar a construção do frigorífico que, já em 1946, abatia mais de 100 suínos/dia. Com a matéria-prima resultante, outros itens como banha, toucinho, carnes salgadas, pernil, presunto, salame, lombo e lingüiça entraram para a lista dos produtos da empresa.

\section{a) Processo de Internacionalização}

Os primeiros contratos de exportação da empresa foram assinados em 1967, quando foram vendidas algumas toneladas de carne bovina e suína in natura, congelada, para o então Mercado Comum Europeu e a Suíça, numa operação em que o valor simbólico superava em muito o econômico. Os anos 60 acabariam por se tornar o marco de entrada da empresa no mercado mundial.

Em 1975 a Sadia iniciou as exportações de frango congelado para o Oriente Médio e assumiu, desde o início, a liderança entre os exportadores nacionais.

Em 1976 inaugurou a Sadia Oeste S.A., em Várzea Grande/MT, dedicada ao abate de bovinos e à exportação de carnes. Já nos primeiros anos o corned beef, a carne cozida congelada e o extrato de carne integraram a pauta de exportação para a Europa e Estados Unidos, enquanto que os cortes bovinos congelados reforçavam as vendas para o Oriente Médio.

Em 1980 foi criada a então Sadia Trading que passou a se responsabilizar pela centralização das operações comerciais no exterior. Neste mesmo ano, as exportações da empresa ultrapassam os US\$ 100 milhões. Novos mercados foram conquistados e a Sadia passou a exportar para o Extremo Oriente, Japão e Hong Kong. O quibe Sadia é exportado até mesmo para o mercado árabe. Finalizou a década de 80 exportando para 40 países e posicionando-se entre os maiores exportadores brasileiros.

Como parte de sua internacionalização, entre 1991 e 1992, a empresa implantou filiais comerciais em Tóquio, Milão e Buenos Aires. Em 1994, com o objetivo de estabelecer um posto de observação no promissor mercado chinês, inaugurou a Churrascaria Beijing Brasil, em Pequim, em Joint Venture com a empresa chinesa Sky Dragon e, em 1996, com os olhos no Mercosul, inaugurou uma central de armazenagem e distribuição em Garin, na Grande Buenos Aires. 
Nos anos 2000, passou a atuar mais agressivamente no mercado externo, com filiais na Argentina, no Uruguai e no Chile; com escritórios comerciais na Itália, Inglaterra e Emirados Árabes; e escritórios de representação no Japão, Paraguai e Bolívia. Em 2007, exportou para mais de 60 nações.

Em 2007, realizou uma Joint Venture com a local Miratog, em Kaliningrado, na Rússia. A unidade recebeu investimentos de R\$ 153 milhões, sendo que R \$ 92 milhões vieram da Sadia e o restante do grupo russo Miratorg, que possui participação de $40 \%$ no empreendimento. A fábrica, que foi batizada de Concórdia, produzirá 53 mil toneladas de presuntos, embutidos e empanados por ano. Será uma unidade processamento de carne - com matérias-primas provenientes do Brasil. Os motivos de entrada podem ser elencados:

- A Rússia é um dos principais mercados de exportação da Sadia, que destina em 2007 cerca de $20 \%$ de seus embarques para o país, equivalente a cerca de 10 mil toneladas de pratos prontos e industrializados de carne. Com a produção local, a empresa pretende ampliar as vendas. O parceiro local é distribuidor dos produtos da empresa na região. Os empanados serão fornecidos para o McDonald's russo. Por um lado, a produção será voltada para empanados de frango e embutidos, sendo que uma parcela de $25 \%$ dos empanados será fornecida ao McDonalds russo. A rede de fast food possui 180 lojas na Rússia e tem planos para crescer $15 \%$ ao ano nos próximos dez anos. Os produtos serão vendidos no mercado russo com a marca Sadia e com a marca Myasnaya Guildia (em português, clube de carne). Enquanto que por outro, os demais produtos serão vendidos no mercado local e em outros países que pertenciam à antiga União Soviética.

- Pretende diminuir a exposição aos embargos impostos pelo governo russo à carne brasileira, já que a fábrica poderá continuar operando com carne russa ou importada da Europa, em caso de embargos ao Brasil. A escolha de Kaliningrado, território situado entre a Polônia e a Lituânia, para receber o investimento da Sadia se justifica pela ausência do imposto de importação de matéria-prima, e porque não há um regime de cotas para importação no local. No restante do país, o imposto de importação sobre a carne suína, bovina e de frango eleva o preço do produto acabado em 4\% a 5\%. Outra vantagem de Kaliningrado é a saída pelo porto no Mar Báltico, que não congela apesar do frio intenso.

- Hoje, a internacionalização da Sadia é considerada uma resposta ao movimento de diversificação de sua maior concorrente (a Perdigão), que está expandindo as atividades para o setor de lácteos. A intenção de instalar uma fábrica na Rússia foi anunciada pela primeira vez no ano de 2006 , em meio à crise provocada pela gripe aviária e depois do fracasso da tentativa de comprar a Perdigão.

Dentro das intenções da empresa para 2008, inclui-se outras duas novas unidades no exterior, com investimentos de R\$ 100 milhões em 2008 e R $\$ 100$ milhões em 2009, com foco em industrialização de carne. Uma delas ficará nos Emirados Árabes. A presença em outros países deixará os negócios da empresa mais estáveis porque vai eliminar o risco de fechamento de mercados por questões sanitárias. Outra vantagem de produzir localmente é a possibilidade de vender produtos refrigerados fora do Brasil, o que não pode ser feito por meio de exportações.

\section{b) Integração Vertical}

$\mathrm{Na}$ produção e abate/industrialização de suínos e aves, a Sadia não atua com integração vertical, mas sim com parceria. Em 1961, institucionalizou o sistema de fomento agropecuário com base no sucesso da parceria entre produtor suinícola e indústria e iniciou, também, a avicultura integrada em Concórdia, aumentando significativamente seu desempenho em produção e abate de frangos, que havia começado, de maneira experimental, em 1956. Atualmente, são 10 mil granjas integradas.

Por outro lado, com relação às atividades de vendas e distribuição dos produtos, criouse, em 1967, a então Sadia Comercial Ltda., que passou a se responsabilizar por toda 
atividade em âmbito nacional, com depósitos em Porto Alegre, Erechim, Porto União, Blumenau, Foz do Iguaçu e com escritórios comerciais em Curitiba, Londrina, Belo Horizonte e Brasília.

\section{c) Grau de Especialização/Diversificação}

A empresa conta com uma diversificada linha de produtos, nos segmentos de suínos, frangos, perus, bovinos, margarinas, pizzas prontas, comida pronta congelada, sobremesas congeladas, rações.

\subsection{Análise dos Resultados}

Conforme os objetivos específicos deste estudo, a análise das abordagens praticadas pelos frigoríficos brasileiros é apresentada nas figuras 1,2, 3 e 4 a seguir.

\begin{tabular}{|c|c|c|c|}
\hline Modo de Entrada & JBS & Marfrig & Sadia \\
\hline Exportações & $\begin{array}{l}\text { Início em } 1997 \\
\text { Em 2007, para mais de } 110 \text { países }\end{array}$ & $\begin{array}{l}\text { Início em } 2001 \\
\text { Em 2007, para mais de } 50 \text { países }\end{array}$ & $\begin{array}{l}\text { Início em } 1967 \\
\text { Em 2007, para mais de } 60 \text { países }\end{array}$ \\
\hline Greenfield & & $\begin{array}{l}\text { 2006, Chile Marfrig Chile } \\
\text { 2007, Uruguai Abate e desossa }\end{array}$ & \\
\hline Aquisições & $\begin{array}{l}\text { 2005, Argentina Swift Armour (3) } \\
\text { 2005, Argentina CEPA (2) } \\
\text { 2006, EUA/Austrália SB Holdings } \\
\text { 2007, EUA/Austrália Swift Food } \\
\text { 2007, Argentina Consig. Rurales } \\
\text { 2007, Argentina Argenvases } \\
\text { 2007, Argentina Frig. Col Car S.A }\end{array}$ & $\begin{array}{l}\text { 2006, Uruguai Elbio R. } \\
\text { 2006, Uruguai La Caballada } \\
\text { 2006, Uruguai Tacuarembó } \\
\text { 2006, Argentina AB\&P } \\
\text { 2006, Uruguai Inaler } \\
\text { 2007, Uruguai Estab. Colônia } \\
\text { 2007, Argentina EDSA } \\
\text { 2007, Argentina Best Beef }\end{array}$ & \\
\hline Alianças Estratégicas & 2007, Itália & $\begin{array}{l}\text { 2006, Chile (50\%) Quinto Cuarto } \\
\text { 2007, Chile }(97,82 \%) \text { Frig. } \\
\text { Patagônia } \\
\text { 2007, Argentina (70,51\%) } \\
\text { Ouickfood }\end{array}$ & \\
\hline Joint Ventures & & & $\begin{array}{l}\text { 1994, China com a Sky Dragon } \\
\text { 2007, Rússia com a Miratog } \\
\text { 2008, Emirados Árabes }\end{array}$ \\
\hline
\end{tabular}

Figura 1 - Modos de entrada com exportações e demais investimentos no exterior pelos frigoríficos

Pode-se notar que o primeiro modo de entrada no mercado internacional das três empresas analisadas foi a exportação. A Sadia iniciou em 1967, levada pelo ambiente de incertezas no país. O JBS, levado pelo movimento de abertura econômica mundial e da conseqüente necessidade de competitividade, busca de eficiência e de novos mercados, em 1997. O JBS exporta para mais de 110 países, e pode-se dizer que o que o possibilita este alto número é a escolha por estar presente com suas plantas em mercados estratégicos. O único mercado estratégico em que o JBS não tem operações é a China. O Marfrig, por fim, iniciou suas exportações em 2001.

Em segundo lugar, após a exportação, por um lado, o JBS e o Marfrig optaram pelas modalidades de aquisições. O JBS fez aquisições em 3 países, onde concentrou sua expansão não só em mercados adjacentes mas também, principalmente, em mercados desenvolvidos. $\mathrm{O}$ Marfrig fez aquisições em 2 países, onde concentrou sua expansão em mercados adjacentes. A Sadia não realizou aquisições.

$\mathrm{Na}$ modalidade de alianças estratégicas, as estratégias das duas empresas são concentradas pela busca dos seguintes tipos de mercados, por um lado o JBS buscando um mercado desenvolvido, enquanto o Marfrig buscando um mercado adjacente.

A Sadia, por outro lado, optou somente pela modalidade de Joint Venture. A estratégia inicial de internacionalização desta empresa compreendeu um mercado emergente, representado pela China. 
Anos 40, no período pós-guerra, o mundo passava por um amplo desenvolvimento industrial, êxodo rural e crescimento das cidades. No Brasil, a industrialização avançava, a urbanização acelerava seus passos e mudavam-se os padrões de consumo alimentar urbano. No âmbito econômico, tem-se o primeiro plano econômico integrado do país, desenhado em 1948, denominado de Plano SALTE (sigla que identificava os objetivos do plano: Saúde, Alimentação, Transporte e Energia).

Anos 50, marcaram o Brasil por um acelerado processo de industrialização. Em meados da década, a indústria ultrapassa significativamente a agricultura na composição do Produto Interno Bruto.

Anos 60, indícios conjunturais - incertezas políticas e inflação - de que a década de 60 não seria favorável aos grandes empreendimentos no Brasil.

Anos 70, o Brasil entra num período econômico favorável, o chamado "milagre econômico".

Anos 80 , se por um lado os anos 80 foram considerados "a década perdida" no âmbito econômico, com altos índices de inflação e a ineficácia de três planos econômicos que tentavam estabilizar a moeda nacional, por outro lado, foram anos marcados por importantes conquistas no âmbito político: o encerramento da primeira fase da transição democrática, manifestações populares exigindo eleições diretas para Presidente e a promulgação da nova Constituição.

Anos 90, o Brasil, no início da década, ainda sofria as conseqüências do descontrole inflacionário, com desequilíbrio da balança comercial e números da produção industrial nos mesmos patamares dos anos 80 . $\mathrm{O}$ Plano Real, em meados da década, dava, finalmente, início à estabilização econômica nacional. O mercado fechado dá lugar ao mercado aberto da concorrência internacional, entra em cena a era do conhecimento, da desestatização, da busca frenética pela competência e competitividade, das parcerias, os países se unem em bloco para competir, as organizações empresariais têm de ser repensadas no que tange a seu foco. Globalização é o nome do jogo.

Décadas de 1990/2000, o Brasil abriu-se para o comércio internacional, facilitando as importações, o plano Real permitiu o controle da inflação em percentuais aceitáveis; o mundo foi marcado pelas crises do México (1995), da Ásia (1997) e da Rússia (1998). Por outro lado, em 1999 o governo adotou uma política cambial que prejudicou os exportadores.

Anos 2000, economia estabilizada, baixos índices de inflação, instituições democráticas consolidadas. A globalização é um fato e novas tendências ganham corpo: fusões, joint ventures, parcerias, alianças estratégicas, e-commerce, logística integrada, governança corporativa, responsabilidade social.

\section{Uruguai - país recebedor de investimentos}

Natural Resource seeking - O Uruguai possui fábricas bem localizadas em regiões de pastos verdes, bem irrigadas, clima temperado, onde o gado torna-se produto de alta qualidade.

Asset seeking - O Uruguai, com rebanho de gado estimado em 11,7 milhões de cabeças em 2006, também é um importante exportador de carne bovina. Neste país, criam-se raças européias, que têm a gordura entremeada, o que garante melhor textura e sabor. A carne desse tipo de gado é vendida por um preço bem superior no mercado mundial. Atualmente, o gado uruguaio é classificado como livre da febre aftosa com vacinação. O Uruguai tem licença para exportar carne in natura para os mercados da América do Norte. 
Market seeking - De janeiro a abril de 2007, os Estados Unidos e Canadá absorveram 63,6\% das exportações de carne bovina do Uruguai, e prevê-se que o México, que também reabriu seu mercado para a carne bovina in natura e desossada do Uruguai em agosto de 2006, se tornará um importante mercado para exportação. As exportações de carne bovina do Uruguai em 2007 devem aumentar devido ao crescimento da demanda no mercado externo, principalmente em países membros do Acordo de Livre Comércio da América do Norte (NAFTA)

\section{Argentina - país recebedor de investimentos}

Asset seeking - A Argentina encontra-se em sexto lugar em produção, com um rebanho estimado em 51,6 milhões de cabeças em 2007.

Efficiency seeking - A Argentina possui indústrias organizadas verticalmente com a produção.

Market seeking - O país é um importante competidor no mercado mundial de carne bovina há muitos anos, encontrando-se em quinto lugar em exportações do produto. A Argentina dispõe de uma cota Hilton - índice que fixa a quantidade de carnes nobres que pode ser exportada para a Europa com descontos tarifários de 29 mil toneladas, enquanto que a do Brasil é de apenas 5 mil ton. O consumo de carne bovina per capita da Argentina é o maior do mundo, $63,3 \mathrm{~kg} / \mathrm{ano}$.

\section{Chile - país recebedor de investimentos}

Market seeking - A carne bovina in natura produzida no Chile não sofre as mesmas restrições da brasileira, podendo a carne bovina in natura chilena ser exportada para os principais mercados consumidores mundiais, incluindo Estados Unidos, Japão, Coréia do Sul e Europa, sendo que para a Europa é permitida ainda a exportação de carne bovina in natura com osso.

\section{Estados Unidos - país recebedor de investimentos}

Efficiency seeking - Os EUA possuem indústrias organizadas verticalmente com a distribuição.

Asset seeking - Os EUA, com rebanho de gado estimado em 97,6 milhões de cabeças em 2007, estão ranqueados em quarto lugar na produção de carne bovina.

Market seeking - O país possui um imenso mercado consumidor (é o país classificado em primeiro lugar nas importações de carne, com $29 \%$ ). O país é o maior consumidor mundial de carne bovina, $25 \%$ e produz $23 \%$. O consumo de carne bovina per capita dos EUA é o segundo maior do mundo, 43,2 kg/ano.

\section{Austrália - país recebedor de investimentos}

Efficiency seeking - A Austrália possui fábricas organizadas verticalmente com a produção.

Asset seeking - A Austrália, com rebanho de gado estimado em 28,4 milhões de cabeças em 2007, também é um importante produtor de carne bovina.

Market seeking - A Austrália é um dos maiores exportadores de carne bovina a países asiáticos.

\section{Rússia - país recebedor de investimentos}

Market seeking - A Rússia, integrante do grupo BRIC, com sua abertura comercial apresenta-se como um mercado novo (é o país classificado em segundo lugar nas importações de carne, com 17\%) e estratégico pela localização e pela posição do país de economia emergente. O país consume $4 \%$ da produção mundial de carne bovina e produz $2 \%$.

\section{China - país recebedor de investimentos}

Market seeking - A China tem apresentado altos índices de crescimento econômico e ingressou recentemente na Organização Mundial do Comércio. Estes e outros fatos têm atraído um grande número de investidores. Mesmo com toda a desigualdade social, o mercado chinês é de extrema relevância na maioria dos mercados. O país consume $15 \%$ da produção mundial de carne bovina.

Figura 2 - Impacto do ambiente institucional do país-sede e dos países recebedores de investimentos

Pode-se chegar à análise, observando-se o ambiente institucional brasileiro no decorrer das décadas, de que os frigoríficos se internacionalizaram como resultado de uma dinâmica econômica desfavorável no país-sede e expandiram-se em busca de mercados, eficiência, recursos naturais e ativos em mercados adjacentes, desenvolvidos e emergentes.

\begin{tabular}{|l|l|l|l|}
\hline \multicolumn{2}{|c|}{ Produto } & \multicolumn{1}{c|}{ JBS } & \multicolumn{1}{c|}{ Madfrig } \\
\hline Bovino & $\begin{array}{l}\text { O maior produtor de carne bovina do } \\
\text { Brasil (18.800), Argentina (6.700) e } \\
\text { Austrália (5.800) e o terceiro maior } \\
\text { produtor nos EUA (20.500). }\end{array}$ & $\begin{array}{l}\text { Brasil } \\
\text { Uruguai (é o maior grupo, } \\
\text { tanto no abate quanto na } \\
\text { exportação, de gado). }\end{array}$ & \\
\hline Ovino & & $\begin{array}{l}\text { Chile } \\
\text { Uruguai }\end{array}$ & \\
\hline Suíno & $\begin{array}{l}\text { Terceiro maior produtor de carne suína } \\
\text { dos EUA (47.900). }\end{array}$ & Brasil & $\begin{array}{l}\text { Brasil } \\
\text { Rússia }\end{array}$ \\
\hline Ave & & & Brasil \\
\hline
\end{tabular}

Figura 3 - Grau de diversificação ou especialização 
Pode-se chegar à análise de que os processos de internacionalização dos frigoríficos JBS e Marfrig possibilitaram a eles a diversificação de produtos, os quais partiram da carne bovina para a suína e ovina, porém não substituindo a importância da carne bovina nos seus negócios, mas sim incrementando seu mix de produtos. Pode-se entender que a especialização não é um pré-requisito para o sucesso.

\begin{tabular}{|c|c|c|c|}
\hline Cadeia & JBS & Marfrig & Sadia \\
\hline Confinamento & $\begin{array}{l}\text { Austrália, Australia Meat } \\
\text { Holdings Pty Limited (AMH) }\end{array}$ & & \\
\hline Cria, Recria, Engorda a campo & Argentina, $A B \& P$ & & \\
\hline Desossa & & $\begin{array}{l}\text { Chile, Quinto Cuarto } \\
\text { Uruguai }\end{array}$ & \\
\hline Embalagem & Argentina, Argenvases & & \\
\hline Transporte & Brasil, Divisão transportes & & \\
\hline Distribuição & $\begin{array}{l}\text { EUA, SB holdings } \\
\text { Itália, Inalca } \\
\text { Chile } \\
\text { Egito } \\
\text { Estados Unidos } \\
\text { Inglaterra } \\
\text { Rússia } \\
\end{array}$ & Brasil, Mabella & Argentina \\
\hline Comercialização & Itália, Montana & $\begin{array}{l}\text { Chile } \\
\text { Reino Unido, Weston }\end{array}$ & $\begin{array}{l}\text { Tóquio } \\
\text { Milão } \\
\text { Buenos Aires } \\
\end{array}$ \\
\hline Escritórios comerciais & & & $\begin{array}{l}\text { Itália } \\
\text { Inglaterra } \\
\text { Emirados Árabes }\end{array}$ \\
\hline Escritórios de representação & & & $\begin{array}{l}\text { Japão } \\
\text { Paraguai } \\
\text { Bolívia } \\
\end{array}$ \\
\hline Churrascaria & & & China \\
\hline
\end{tabular}

Figura 4 - Organização/coordenação interna: Internalização

Concluindo a análise, a Figura 5 resume as principais teorias econômicas e ajuda verificar a aderência das abordagens praticadas nos processos de internacionalização da JBS, Marfrig e Sadia com as mesmas.

\begin{tabular}{|c|c|c|c|c|c|c|c|c|c|c|c|c|c|c|}
\hline Autor/Teoria & 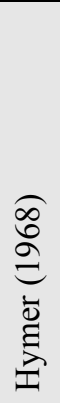 & 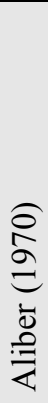 & 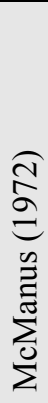 & 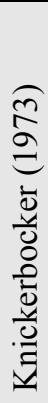 & 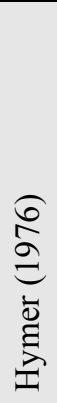 & 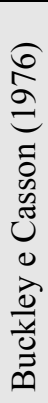 & 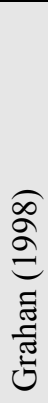 & 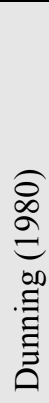 & 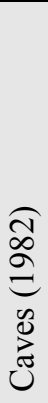 & 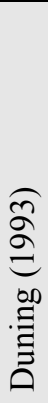 & $\tilde{\Leftrightarrow}$ & $\frac{\underbrace{\infty}_{\Xi}}{\sum_{\Xi}^{ \pm}}$ & 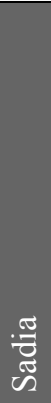 & 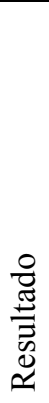 \\
\hline Vantagens especificas & & & & & + & & & + & & & + & + & + & + \\
\hline Diversificação & & & & & + & & & & & & + & + & + & + \\
\hline Integração vertical & + & & + & & & + & & & + & & + & + & + & + \\
\hline $\begin{array}{l}\text { Barreiras tarifárias e } \\
\text { não-tarifárias }\end{array}$ & & + & & + & & & & & & & + & + & + & + \\
\hline $\begin{array}{l}\text { Estruturas } \\
\text { oligopolísticas }\end{array}$ & & & & + & & & + & & & & + & + & + & + \\
\hline Integração diversificada & & & & & & & & & + & & + & + & + & + \\
\hline $\begin{array}{l}\text { Market, Asset, Resource } \\
\text { seeking }\end{array}$ & & & & & & & & & & + & + & + & + & + \\
\hline
\end{tabular}

Figura 5 - Análise dos resultados: aderência com a teoria 


\section{Discussões Conclusivas e Sugestões para Pesquisas Futuras}

Considerando-se que os fluxos de FDI de empresas brasileiras para o exterior é recente, mas que os fluxos de investimentos externos inward são uma realidade há mais tempo, se quiserem avançar em market share, as empresas precisam estar dispostas a estratégias agressivas, como por exemplo, as opções para expandirem os negócios montando um novo parque industrial no exterior ou comprando um já em funcionamento. No caso da Joint Venture, as empresas se juntam para ganhar escala, tecnologia, por outro lado, em se tratando de aquisições, o mercado financeiro é rico em instrumentos, como por exemplo a venda de ações em bolsa, que podem tornar esta modalidade viável. No caso das três empresas analisadas, conclui-se que as estratégias resumem-se em estender suas operações através da aquisição de empresas estratégicas em mercados adjacentes, desenvolvidos e emergentes e de Joint Ventures com líderes mundiais nos países centrais.

$\mathrm{O}$ avanço dos frigoríficos brasileiros nos países vizinhos tem o objetivo de facilitar o acesso a mercados para onde o Brasil tem dificuldade para exportar. Além disso, as empresas ganham "portas" de fuga em caso de dois problemas que possam afetá-las em qualquer dos mercados: a taxa de câmbio e eventuais bloqueios por problemas sanitários, como febre aftosa.

É importante ressaltar que, embora a estratégia de internacionalização das empresas tenha começado na Argentina, Uruguai e Chile, estas não ocorreram por estes serem países vizinhos, conforme preconiza a teoria comportamental, mas sim porque as empresas internacionalizaram na busca de explorar soluções internacionais, ou seja, transpor barreiras sanitárias e não-sanitárias; pelo fato de as empresas adquiridas possuírem alta tecnologia; e por possuírem marcas e mercados consolidados, além de integração vertical com parte da produção. Isso comprova a aderência à teoria econômica de Dunning (1993), pela busca de mercados, ativos, recursos e eficiência.

Ainda, analisando-se pela teoria econômica do Paradigma Eclético (Dunning, 1980), as empresas buscaram os três tipos de vantagens: de propriedade, de localização e de internalização. A primeira, vantagem de propriedade, foi buscada nas aquisições realizadas (compraram $100 \%$ do capital de empresas já instaladas e que possuíam reconhecimento em marca, conhecimento tácito, domínio de tecnologia própria na produção, capacidade de $\mathrm{P} \& \mathrm{D}$ de novos produtos, o que permite produção customizada e flexibilidade, grande capacidade instalada para produção). A segunda, vantagem de localização das subsidiárias, foi buscada através da localização das filiais em mercados estratégicos (adjacente, desenvolvido e emergente) buscando principalmente contornar as barreiras protecionistas impostas por governos locais. E, por último, a vantagem de internalização, pela busca de aquisição de negócios que envolviam integração vertical entre a produção e a indústria ou entre a produção e a distribuição.

De maneira geral, também, os processos de internacionalização dos frigoríficos JBS, Marfrig e Sadia confirmam as teorias de Hymer (1968), Aliber (1970), McManus (1972), Knickerbocker (1973), Buckley e Casson (1976), Grahan (1998).

Sugere-se, em pesquisas futuras, trabalhos com a inclusão de duas outras empresas do setor, o Grupo Bertim (representado pela Bertim couros e pela Bertim alimentos) e a Perdigão. A Bertim couros porque ingressou recentemente na Província de Guandong na China, através de Joint Venture, e a Bertim alimentos que, em 2006, adquiriu o Frigorífico Canelones no Uruguai. O Grupo Bertim segue uma rigorosa estratégia de verticalização. A Perdigão, por sua vez, porque adquiriu, em 2007, a empresa de alimentos Plusfood, do Reino Unido, fabricante de hambúrgueres, grelhados e nuggets, e que tem forte presença no mercado de outros países europeus.

Outra questão que pode ser levantada é em relação a análise dos processos de internacionalização sob a ótica da competitividade. Os frigoríficos brasileiros podem estar 
internacionalizando por motivo de competitividade, principalmente no mercado interno. Para a Sadia, por exemplo, a internacionalização visa muito garantir seu espaço em um cenário muito mais competitivo no mercado interno. A entrada dos frigoríficos de carne bovina no setor de aves, sinalizada no final de 2007 pelo Bertim, assim como no setor de suínos, como efetivado pelo JBS nos EUA, é mais um indício de que a concorrência será muito mais dura nos próximos anos para a Sadia no Brasil, o que reforça a importância das novas operações no exterior. Quanto ao JBS e ao Marfrig, o market share no mercado de bovinos também é ameaçado por competidores internacionais que venham a se estabelecer no país com o maior rebanho de bovinos do mundo.

Uma análise complementar que pode ser realizada, ainda, é a questão da aprendizagem tecnológica. O JBS decidiu trazer para o Brasil o modelo de negócios usado pela Swift, projeto que exigirá uma estrutura para confinamento de bois e uma ampla parceria com produtores de grãos e criadores integrados de suínos. Com pensamento inovador, a Swift tornou-se uma indústria pioneira de novas idéias, produtos e tecnologia. Já o Marfrig, possui instalações modernas com capacidade de fabricar produtos de alto valor agregado. As plantas foram todas adquiridas ou construídas nos últimos sete anos e foram projetadas ou estão sendo modernizadas para produzir uma ampla variedade de produtos de carne bovina, incluindo produtos de alto valor agregado, como cortes de carne bovina de alta qualidade e carne bovina cozida congelada. As modernas instalações da empresa propiciam acesso a clientes, como redes mundiais de supermercados, que exigem os mais altos padrões de qualidade de seus fornecedores.

\section{Referências}

ALIBER, R. Z. A theory of foreign direct investment. In: C.P. Kindleberger (ed.) The International Corporation. Cambridge: MIT Press, 1970.

BUCKLEY, P.; CASSON, M. A long-run theory of the multinational enterprise, 1976.

CAVES, R. E. International corporations: the industrial economics of foreign investment. Economica, vol 38 february, pp. 1-27, 1971.

University Press, 1982.

Multinational enterprise and economic analysis. Cambridge: Cambridge

COASE, R. The nature of the firm. Economica, 4(16), pp. 386-405, 1937.

. The problem of social cost. Journal of Law and Economics, 3(1), pp. 1-44, 1960.

CYERT, R.; MARCH, J. A behavioral theory of the firm. Englewood Cliffs: Prentice-Hall, 1963.

DUNNING, J. Trade, location of economic activity and MNE: a search for an eclectic approach. International Allocation of Economic Activity: Proceedings of a Nobel symposium held at Stockholm. pp. 395-418. London: Macmillan, 1977.

Towards an eclectic theory of international production: some empirical tests.

Journal of International Business Studies, 11(Spring), pp. 9-31, 1980.

Wesley, 1993.

Multinational enterprises and the global economy. Workhingan: Addison-

. Alliance capitalism and global business. Routledge, London \& New York, 1997.

GRAHAM, E. M. Market structure and the multinational enterprise: a game-theoretic approach. Journal of International Business Studies, 29, pp. 67-83, 1998.

GRUBER, W. et al. The R\&D factor in international trade and investment of United States industries, Journal of Political Economy, February, pp.20-37, 1967.

HENNART, J-F. A theory of multinational enterprise. University of Michigan Press. Ann Arbor, MI, 1982.

HYMER, S. The international operations of national firms: a study of direct foreign investment. Cambridge, MA: MIT Press (Doctoral dissertation, MIT, 1960). 1976. 
. The large multinational corporation: an analysis of some motives for the international integration of business. Revue Economique, 19(6), pp. 949-973, 1968. JBS - Disponível em www.friboi.com.br. Acesso em 10/12/2007.

JOHANSON, J.; VAHLNE, J.-E. The internationalization process of the firm - a model of knowledge development and increasing foreign market commitment. Journal of International Business Studies, 8(1), pp. 23-32, 1977.

JORNAL ESTADO DE SÃO PAULO - Disponível em www.estadao.com.br. Acesso em 10/12/2007.

KNICKERBOCKER, F. T. Oligopolistic reaction and multinational enterprise. Cambridge, MA: Division of Research, Graduate School of Business Administration. Harvard University, 1973.

MARFRIG - Disponível em www.marfrig.com.br. Acesso em 10/12/2007.

McMANUS, S. The theory of the international firm. In: G. Paquet (Ed.), The multinational firm and the nation state. pp. 66-93, Toronto: Collier-Macmillan, 1972.

PENROSE, E. The theory of the growth of the firm. New York: Oxford University Press, 1959.

PORTER, M. E. Competition in global industries: a conceptual framework. In: Porter, M.E. (ed.) Competition in global industries, Harvard Business School Press, Boston, 1986.

RUGMAN, A. M. Inside the multinationals. Columbia University Press, New York, 1981.

SADIA - Disponível em www.sadia.com.br. Acesso em 10/12/2007.

UNCTAD - United Nations Conference on Trade and Development. World Investment Report 2007 - Transnational Corporations, Extractive Industries and Development. 2007. Disponível em http://www.unctad.org/wir. Acesso em 20/10/2007.

VERNON, R. International investment and international trade in the product cycle. Quarterly Journal of Economics, 80, pp. 190-207, 1966.

. The location of economic activity. In: John H. Dunning (ed.) Economic analysis and the multinational enterprise. London: George Allen \& Unwin, 1974.

.The product cycle hypothesis in the new international environment. Oxford Bulletin of Economics and Statistics, 41, November, p.255-67, 1979.

WILLIAMSON, O. E. Markets and hierarchies. New York: Free Press, 1975.

YIN, R. K. Case study research: design and methods. 2. ed. Sage publications, Thousand Oaks, CA, 1994. 